\title{
Semi-automatic Assessment Process in a Ubiquitous Environment for Language Learning
}

\author{
M. Paredes ${ }^{1}$, M. Ortega ${ }^{2}$, P.P. Sánchez-Villalón ${ }^{2}$, M.A. Redondo ${ }^{2}$, C. Bravo $^{2}$, and \\ J. Bravo $^{2}$ \\ ${ }^{1}$ Escuela Superior de Ciencias Experimentales y Tecnología, \\ Universidad Rey Juan Carlos \\ 28933 Móstoles, Madrid \\ m.paredes@escet.urjc.es \\ ${ }^{2}$ Escuela Superior de Informática, Paseo de la Universidad s/n, \\ Universidad de Castilla La Mancha \\ 13071 Ciudad Real \\ Manuel.Ortega@uclm.es
}

\begin{abstract}
This work presents a research on the methods and mechanisms necessary to bring the Information and Communication Technologies in the traditional classroom. This will be achieved by putting collaborative and Ubiquitous Computing paradigms together to integrate both fields into the educational environment. As a study case we have developed a system for language learning, in particular English as a Foreign Language (EFL), through a composition writing activity in group.
\end{abstract}

\section{AULA: A Ubiquitous Computation Environment for the Collaborative Composition of Documents}

At present, ubiquitous applications and systems applied in the environment of the classroom are scarce and they provide little collaborative work in group support. The existing applications or systems [1-5] satisfy some scenario needs that we suggest, but not all. These applications do not satisfy our domain's needs because of two reasons: the application is not sensitive to the user context and the collaborative tools do not support the proposals discussion process.

The AULA system is composed of: a projection whiteboard and other edition whiteboard, a data base server, the Localization Manager (providing context-aware to the system), the Session Coordinator and the mobile devices (PDA) (each student has his own PDA). The communication technologies used are: a wireless network (RF), ultrasonic and infrared communications. The system architecture is described with more detail in [6]. When the class starts, the teacher indicates the main subject of the document and other characteristics or properties that he considers appropriate to the students. After this first phase, a brainstorming process about the composition subject starts. Now the student can make use of collaborative tools (see Figure 1 and 2). The system structures all the information resulting from the brainstorming process into the 
aspects, which are broken down into several ideas. The process of discussion finishes when the group of students get to an agreement, accepting some aspects and ideas suggested and refusing others, through a polling process provided by the system.

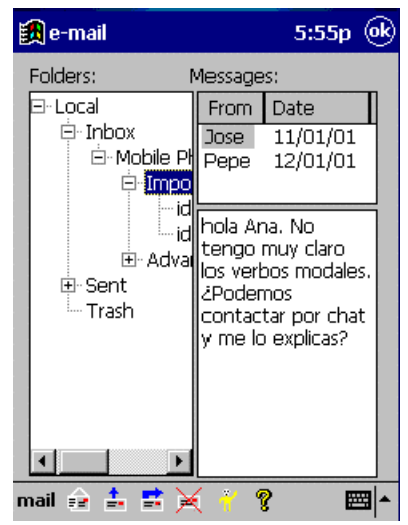

Fig. 1. Electronic mail tool.

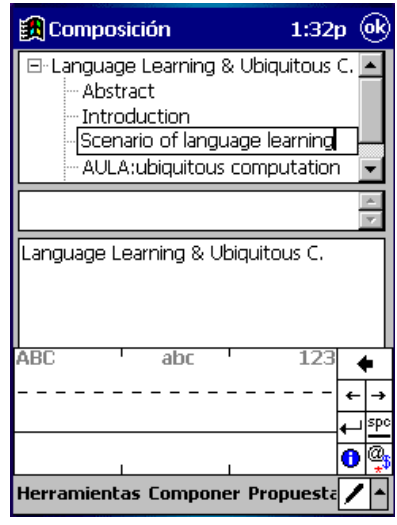

Fig. 2. Inserting \& proposing an Aspect.

\section{Assessment Tools for the Teacher}

AULA system offers help for the teacher with some tools accessible through a desktop PC. These tools help the teacher to do several tasks, such as: defining parameters about the type of composition, carrying out a follow-up study of the construction process and evaluating the students and the group. The collaborative activity closer to composition writing we can think of in a typical class of English is one based on writing projects in groups. Here, the teacher carries out the evaluation through a postproduction process, consisting of the teachers establishing a dialogue with the students or just analyzing the results. The teacher evaluates the activity marking two aspects: the resulting document(s) provided by the group of students and the teacher's memory and ability to infer about every student's performance in the project development process. This system of evaluation is really complex for the teacher.

In the composition processes, this evaluation phase is one of the hardest due to the emotional implication. Evidently, in this situation teachers wonder about this type of questions: Who has suggested this particular idea? Has this student taken part in the process of discussion actively? To what extent? Did such a student contribute proposals with aspects and ideas to the group?. We should keep in mind the indicators of effective collaborative learning as shown in Soller [7]. AULA system traces and records the students' actions and through a synthesis process it can provide answers to such questions. This way, the teacher will receive help to analyze questions such as: the progress of each student in their language development (globally as well as in particular areas), the student's reaction to errors made by other members of the group or the history participation of a student in previous activities. 
This synthesis process generates some conclusions about the working process and solution provided by the group (see Figure 3). The system infers these conclusions based on two types of information: the traces (the actions carried out by the students) and the information about the quality of the solution. This last information is provided by the teacher. The teacher analyzes the document suggested by the group and gives his/her opinion about aspects such as the grammatical accuracy or the communication ability. The inference system consists in linking attributes isolated from the user with processes of action. These processes of action are blocks of information, which define communicative characteristics of the user and of the group in the activity of writing compositions.

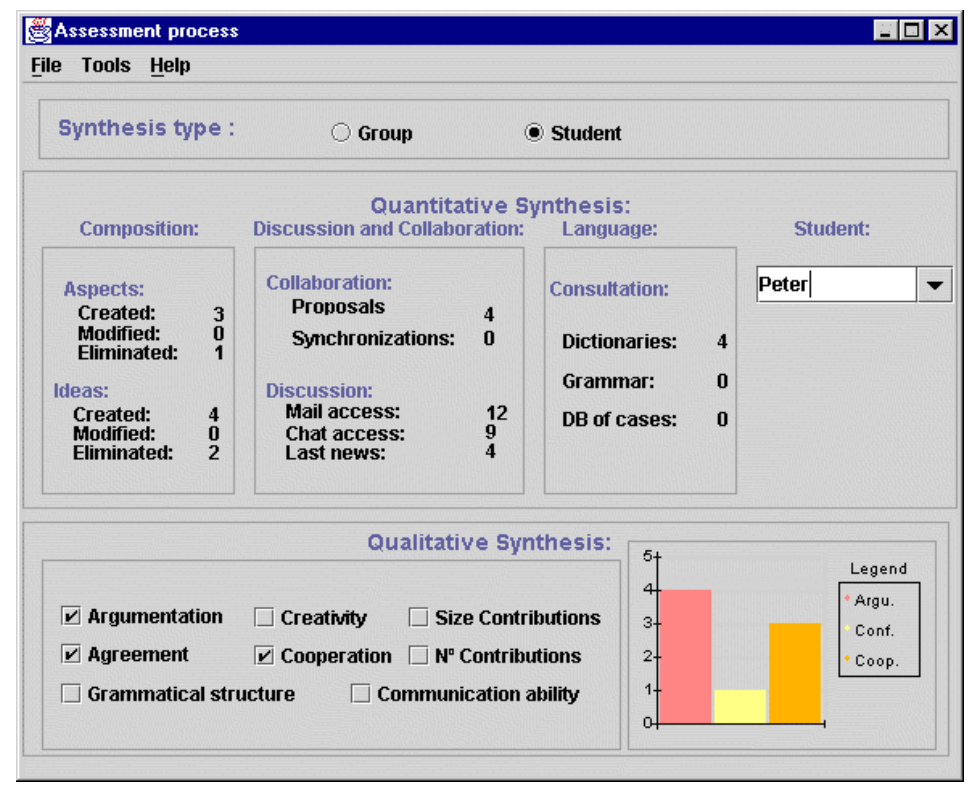

Fig. 3. Synthesis process result.

The process of synthesis is composed of two subprocesses: quantitative synthesis and qualitative synthesis as a way in which other systems have developed the assessment process [8]. On the one hand, the subprocess of quantitative synthesis shows information about the times that a student has performed some actions, such as the number of proposals (aspects or ideas) sent, modified or erased by a student, the number of times that a student has accessed the email facility, etc. On the other hand, the subprocess of qualitative synthesis informs about the characteristics of a student's profile, such as whether the student was active and decisive during the composition activity, or on the contrary, if the student was passive and hesitant in their proposals, whether the student took part in the processes of discussion and put proposals forward and succeeded, or else, if the student did not take part in the group discussions. We can make the process of synthesis (quantitative as well as qualitative) for each student or for the group. 
In order to carry out this individual and group synthesis process, we need to establish a mechanism which structures all the information generated throughout the composition process. The actions carried out by the user about the written composition and use of tools (collaborative as well as language tools) are structured in user's traces. Therefore, every time the student executes an action, in the database of the system an entry is created and the student's trace is written. Finally, the teacher chats with the group about the conclusions and the corrections of the composition.

Acknowledgements. This work was partially supported by the Junta de Comunidades de Castilla - La Mancha and the Ministerio de Ciencia y Tecnología in the Projects PBI-02-026 and TIC2002-01387.

\section{References}

1. Roth, J., Unger, C.; Using Handheld Devices in Synchronous Collaborative Scenarios., Proceedings of the Second International Symposium on Handheld and Ubiquitous Computing, pp.187-199, Springer. Bristol, U.K., Sept. 2000.

2. Baldonado, M., Steve, C., Gwizdka, J., Paepcke, A.; Notable: At the Intersection of Annotations and Handheld Technology., Proceedings of the Second International Symposium on Handheld and Ubiquitous Computing, pp.100-113, Springer. Bristol, U.K., Sept. 2000.

3. Myres, B.A., Stiel, H., Gargiulo, R.; Collaboration Using Multiple PDAs Connected to a PC., Proceedings of the ACM 1998 conference on Computer Supported Cooperative Work, pp. 285-294, Seattle, Washington, USA, 1998.

4. Danesh, A., Inkpen, K., Lau, F., Shu, K., Booth K.; Geney ${ }^{\mathrm{TM}}$ : Designing a Collaborative Activity for the Palm ${ }^{\mathrm{TM}}$ Handheld Computer., Proceedings of the SIGCHI'01, pp. 388-395, Seattle, Washington, USA, 2001.

5. Zurita, G., Nussbaum, M.; Mobile CSCL Applications Supported by Mobile Computing., Pontificial Catholic University of Chile, Ret. Feb. 14, 2002 from http://julita.usask.ca/mable/Accepted.htm\#Submission6

6. Ortega, M., Redondo, M.A, Paredes, M, Sánchez-Villalón, P.P., Bravo, C., Bravo, J.; Ubiquitous Computing and Collaboration: New paradigms in the classroom of the $21 \mathrm{st}$ Century., Computers and Education: Towards an Interconnected Society, M. Ortega and J. Bravo (Eds.), Kluwer Academic Publishers (2001), pp. 261-273.

7. Soller A.L.; Supporting Social Interaction in an Intelligent Collaborative Learning System, International Journal of Artificial Intelligence in Education, Volume 12, pp. 40-62 (2001).

8. Barros, B., and Verdejo, M.F.; An approach to analyse collaboration when shared structured workspaces are used for carrying out group learning processes., Proceedings of Artificial Intelligence in Education. IOS Press, S. Lajoie and M. Vivet (Eds.), pp. 449-456. (1999). 